\title{
Working profile and knowledge of community health workers under Janani Suraksha Yojana, Scheme
}

\author{
VINITA PANDEY* AND SUKHJEET KAUR \\ Department of Home Science Extension and Communication Management, Faculty of Home Science, \\ Punjab Agricultural University, LUDHIANA(PUNJAB) INDIA
}

\begin{abstract}
The present study was conducted in three socio-cultural zones of Punjab i.e. Malwa, Majha and Doaba to assess the knowledge of the health functionaries regarding Janani Suraksha Yojana (JSY) and its relationship with socio-economic profile of the functionaries. Majority of the functionaries of Majha, Malwa and Doaba regions of Punjab were in the age group of 28-35 years, married, educated upto senior secondary level and belonged to SC category, earned upto Rs. 50000 per annum. Majority of the functionaries had 6-10 years of work experience. Majority of the functionaries of all the zones of Punjab had high level of knowledge about procedure, flow of fund under Janani Suraksha Yojana (JSY) while medium level of knowledge about basic knowledge regarding Janani Suraksha Yojana $(J S Y)$. Majority of the functionaries of all the zones had high level of overall knowledge about Janani Suraksha Yojana. It was also found that socio-economic variables were associated with level of knowledge of functionaries. Out of this education, respondents' income, mass media exposure, were significantly associated with level of knowledge at 1 per cent level of significance while work experience was associated at 5 per cent level of significance.
\end{abstract}

Key Words : Socio-cultural zones, Janani Suraksha Yojana, Knowledge level, Socio-economic characteristics functionaries

View Point Article : Pandey, Vinita and Kaur, Sukhjeet (2017). Working profile and knowledge of community health workers under Janani Suraksha Yojana, Scheme. Internat. J. Home Sci. Extn. \& Comm. Manage., 4 (1): 7-14. DOI : 10.15740/HAS/IJHSECM/ 4.1/7-14.

Article History : Received : 16.08.2016; Revised : 17.11.2016; Accepted : 03.12.2016

\footnotetext{
* Author for correspondence (Email : Vinitapandey890@gmail.com)
} 